\title{
Energy Flexibility Assessment of a Multi Agent-based Smart Home Energy System
}

\author{
Amin Shokri Gazafroudi, Tiago Pinto, \\ Francisco Prieto-Castrillo, Juan Manuel Corchado \\ BISITE Research Group, Universidad de Salamanca \\ Salamanca, Spain \\ \{shokri, tpinto, franciscop, corchado\}@usal.es
}

\author{
Omid Abrishambaf, Aria Jozi, \\ Zita Vale \\ GECAD, IPP - Polytechnic of Porto \\ Porto, Portugal \\ \{ombaf,arjoz, zav\}@isep.ipp.pt
}

\begin{abstract}
Power systems worldwide are complex and challenging environments. The increasing necessity for an adequate integration of renewable energy sources is resulting in a rising complexity in power systems operation. Multi-agent based simulation platforms have proven to be a good option to study the several issues related to these systems. In a smaller scale, a home energy management system would be effective for the both sides of the network. It can reduce the electricity costs of the demand side, and it can assist to relieve the grid congestion in peak times. This paper represents a domestic energy management system as part of a multi-agent system that models the smart home energy system. Our proposed system consists of energy management and predictor systems. This way, homes are able to transact with the local electricity market according to the energy flexibility that is provided by the electric vehicle, and it can manage produced electrical energy of the photovoltaic system inside of the home.

Index Terms-Smart home, energy management system, multi agent system, optimization problem.
\end{abstract}

\section{INTRODUCTION}

Nowadays, according to the daily increment of electricity demand, the utilization of Distributed Renewable Energy Resources (DRER) is an opportunity to assist the power distribution network [1]. DRER, such as Photovoltaic (PV) system and wind turbine, are moving the current power grid toward the elimination of centralized power plants [2]. DRER have several benefits for the power grid, namely, they decrease the greenhouse gas emissions, relieves the grid congestion, and decrease the costs related to the electricity production [3]. However, the integration of DRER into the current power grid, leads to have network management and stability problems [4].

In a smaller scale, a Domestic Energy Management System (DEMS) enables the domestic customers to manage their consumption in order to minimize the electricity bills. For implementing a DEMS, several infrastructures are required, such as sensors for real-time monitoring and actuators for controlling the equipment [5]. Concerning the management of DEMS, two methods can be proposed. The centralized control where a powerful central controller unit and communication between this unit and each single component of the DEMS is required. This is an expensive method and in the case of failure in a component, all of the system may be effected [6]. The second scheme is the Multi Agent System (MAS), where the decisions take place in the local controllers based on the real-time data acquired by the other components [7]. The MAS method is preferred when comparing with centralized control, since if any fault occurs in the DEMS, the faulty agent can be easily eliminated and the system is able to continue its operation [8]. Additionally, MAS is more cost-effective [9], tolerant, adaptive, and flexible for the DEMS [10]. Before the massive implementation of business model related to the DEMS, the need of simulations and survey the behavior of each components is evident. Intelligent methods such as MAS simulations are satisfying for conveying the complex models with dynamic interactions [11].

In this paper, we present a Multi Agent-based Smart Home Energy System (MASHES). The MASHES consists of different agents each of whom have different tasks in the system. Also, our proposed DEMS is defined to manage electrical energy inside the home. Also, the home is able to trade energy with the Local Electricity System (LEM) to maximize its expected profit according to the energy flexibility that is provided by the Electric Vehicle (EV). Also, an interval method is used to model uncertainty of the decision-making variables. In this interval methods, uncertainty is modeled based on the bands that depend on the central and error forecasting of the stochastic variables that are provided by the predictor system in this paper.

The rest of this paper is organized as follows. Section II introduces the proposed predictor system. Then, the proposed domestic energy management problem formulation is described in Section III and the hardware implementation is described in Section IV. Besides, the simulation results of the case study are illustrated in Section V. Finally, the findings of the paper are summarized in Section VI.

\section{Predictor System (PS)}

PS is an agent that must provide the accurate prediction of all the stochastic variables of the system such as solar radiation, weather temperature and electrical non-shiftable loads. The outputs of this agent will be the inputs of the DEMS. In this paper, the prediction methodology is used to achieve the required forecasted values is based on Hybrid Neural Fuzzy Inference System (HyFIS). 


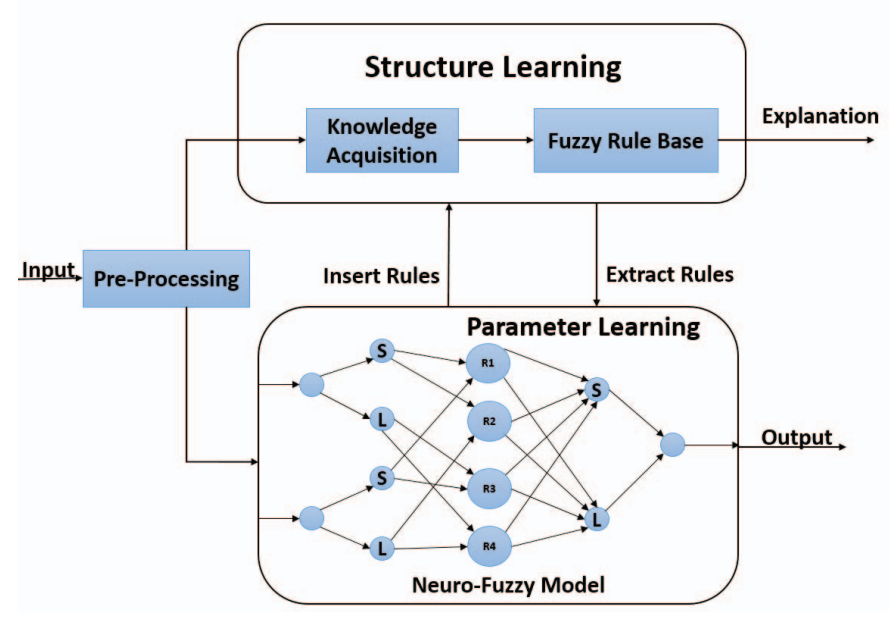

Fig. 1. General schematic diagram of the HyFIS [15].

\section{A. Hybrid Neural Fuzzy Inference System}

To generate the fuzzy rules, the learning process in HyFIS method is divided in two phases, which are [12]:

- Structure learning, i.e. finding the rules by using the knowledge acquisition module;

- Parameter learning phase in order to tune the fuzzy membership functions [13] to achieve a desired level of performance.

This approach can be easily updated when there is new available data [14] which is one of the advantage of using this method. As the Fig. 1 shows, while there is a new available pair data, the fuzzy rule base will be updated by a new rule, created for this data.

In the first phase, a multi-layered perceptron (MLP) network based on a gradient descent learning algorithm is used by the neuro-fuzzy model to adapt the parameters of the fuzzy model [16]. Learning from data and approximate reasoning is simplifies by this architecture, as well as knowledge acquisition. It allows using the combination of both numerical data and fuzzy rules thus producing the synergistic benets associated with the two sources.

A multi-layer Artificial Neural Network(ANN), based on a combination with fuzzy systems is the proposed neuro-fuzzy model in the HyFIS. As the Fig. 2 shows this system is divided in five layers. In this structure, the input and output nodes are the input state and output control/decision signals respectively. In the hidden layers, the nodes detain the responsibility of representing the membership functions and rules.

The first layer includes the nodes which are the inputs that transmit input signals to the next layer. The nodes in the second and fourth layers, are the term nodes. The term nodes act as membership functions to express the inputoutput fuzzy linguistic variables. The fuzzy sets defined for the input-output variables are divided in three groups: Large (L), Medium (M), and Small (S) in these layers. Although, in some implementations or specific cases, these can be divided in more specific groups as, e.g. Large Positive (LP), Small

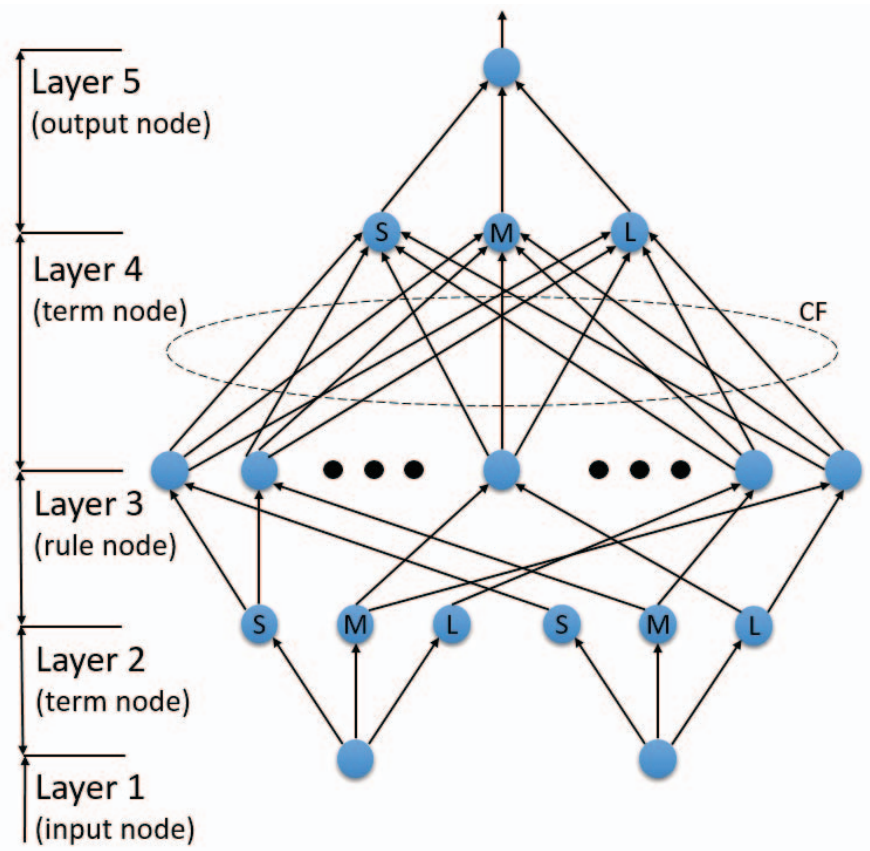

Fig. 2. The structure of the Neuro-Fuzzy model from the HyFIS architecture [15].

Positive (SP), Zero (ZE), Small Negative (SN), and Large Negative (LN).

The third layer includes the rule nodes, where every node represents one fuzzy rule. The connection weights between the third and fourth layer represent certainty factors of the associated rules, i.e. each rule is activated to a certain degree controlled by the weight values. Finally, the nodes in the last layer represent the output of the system.

\section{Domestic Energy Management System}

The task of DEMS is to make optimum decisions in the MASHES. In this case, DMS faces a discrete optimization problem. We propose that there are two LEMs: Day-ahead Local Electricity Market (DALEM) and Real-Time Local Electricity Market (RTLEM). Hence, each smart home can participate in the DALEM and RTLEM. In this paper, the Domestic Energy Management (DEM) problem is modeled as a two-stage problem. The first stage is called Day-Ahead (DA) stage, and the second stage is called the Real-Time (RT) stage.

\section{A. Objective Function}

Here, the objective is to maximize the Expected Profit (EP) of energy services in the DALEM and RTLEM simultaneously. In this work, the PV system is the only Distributed energy Resource (DER) that is considered. EV exists as an Energy Storage System (ESS) in the MASHES. Also, Electrical Loads (ELs) consist of Space Heater (SH), Storage Water Heater (SWH), Pool Pump (PP), and Must-Run Services (MRSs).

$$
E P=E P^{d a}+E P^{r t}
$$




\section{B. Day-Ahead Stage}

DA stage obtains optimum decisions for the system in day d-1. Hence, the EP for the DA stage is represented as (2):

$$
E P^{d a}=\sum_{t=1}^{N_{t}}\left(\lambda_{t}^{\prime} P_{p v, o u t_{t}}^{d a}-\lambda_{t} P_{n e t_{t}}^{d a}\right)
$$

$E P^{d a}$ consists of two parts. While the first part represents the revenue of selling the electrical energy produced by the PV system to the DALEM, the second part states the costs of buying the electrical energy from the DALEM. The constraints of the DA stage are:

$$
\begin{aligned}
& P_{n e t_{t}}^{d a}+P_{p v, i n_{t}}^{d a}=\sum_{j=1}^{N_{j}} L_{j_{t}}^{d a} \\
& -S_{\text {max }} \leq P_{\text {net }_{t}}^{d a}-P_{\text {pv, out }}^{d a} \leq S_{\text {max }}
\end{aligned}
$$

Eq. (3) establishes the power balance equation due to the power output of the PV system that is injected into the home, $P_{p v, i n_{t}}^{d a}$, grid power input, $P_{n e t_{t}}^{d a}$, and electrical loads, $L_{j_{t}}^{d a}$. In this paper, power loss is not considered for simplicity. Eq. (4) represents the power flow limitation through the distribution line which ends at the building. $S_{\max }$ expresses the maximum power capacity of the distribution line that links the enduser and the power grid. Moreover, there are some limitations corresponding to all appliances. It is noteworthy that the power produced/consumed of all devices have been considered to be equal to its central predicted amount at this stage because the uncertainty is not considered in the DA stage.

$$
\begin{aligned}
& P_{p v_{t}}^{d a}=P_{p v, i n_{t}}^{d a}+P_{p v, o u t_{t}}^{d a} \\
& P_{p t_{t}}^{d a}=P_{p v_{t}}^{p r e d} \\
& L_{j_{t}}^{d a}=L_{j_{t}}^{p r e d} \\
& \sum_{j=1}^{N_{j}} L_{j_{t}}^{d a}=L_{s h_{t}}^{d a}+L_{s w h_{t}}^{d a}+L_{m r s_{t}}^{d a}
\end{aligned}
$$

The total power generation of the PV system is stated in Eq. (5). Eq. (6) states the power output limitations of PV. Besides, Eq. (7) represents the electrical power consumed by ELs agents.

\section{Real-Time Stage}

In this stage, the expected profit of the smart home due to participating in the RTLEM is defined. The objective function of the RT stage, $O F^{r t}$, is represented as:

$$
\begin{aligned}
& E P^{r t}=\sum_{t=1}^{N_{t}}\left(\lambda_{t}\left(P_{p v, \text { out }}^{r t}-P_{p v, \text { out }}^{\text {da }}\right)\right. \\
& \left.+\lambda_{t} P_{\text {dis, out }}^{r t}-\lambda_{t} P_{c h_{t}}^{r t}-\sum_{j=1}^{N_{j}} V O L L_{j} L_{j_{t}}^{s h e d}-V_{p v}^{s} S_{p v_{t}}\right)
\end{aligned}
$$

$O F^{r t}$ consisting of five parts. The first part represents the revenue for selling energy produced by the PV system to the RTLEM. The total cost of electrical energy that is bought from the RTLEM is represented in the second part. The third part expresses the profit due to selling the stored electrical energy of the EV to the RTLEM. Also, the charging cost of the EV is represented in the forth term. The Value of Loss Load (VOLL), $V O L L_{j}$, is stated in the fifth part. Finally, the spillage cost of the PV system is represented in the last part. As seen in Eq. (9), it is proposed that if the PV power generation in the RT stage, $P_{p v, \text { out }}^{r t}$, is more than the PV power generation in the DA stage, the smart home can only sell its extra power at the net price, $\lambda$, that is less than the price that is established for the purchase of the power generated by the PV on the DALEM, $\lambda^{\prime}$. In the RT stage, Eq. (10) is the power balance equation, and Eq. (11) shows the power flow limitation in a distribution line. Also, there are specific definitions for all appliances in the DEMS whose uncertainties are considered.

$$
\begin{aligned}
& P_{n e t_{t}}^{r t}+P_{p v, i n_{t}}^{r t}+P_{d i s, \text { in }_{t}}^{r t}=\sum_{j=1}^{N_{j}}\left(L_{j_{t}}^{r t}-L_{j_{t}}^{\text {shed }}\right)+P_{c h_{t}}^{r t} \\
& -S_{\text {max }} \leq P_{\text {net }_{t}}^{r t}-\left(P_{\text {pv, out }}^{r t}+P_{{\text {dis }, \text { out }_{t}}_{t}}^{r t} \leq S_{\text {max }}\right.
\end{aligned}
$$

1) PV System: The power output of the PV panels in the RT stage, $P_{p v_{t}}^{r t}$, is obtained based on Eq. (12). Where as Eq. (12), $P_{p v, p_{t}}^{r t}$ is the potential power generation of the PV system in the real-time, and $S_{p v_{t}}$ is the spillage power of the PV. Eq. (13) determines $P_{p v, p_{t}}^{r t}$ according to the interval predicted bands.

$$
\begin{aligned}
& P_{p v_{t}}^{r t}=P_{p v, p_{t}}^{r t}-S_{p v_{t}} \\
& P_{p v_{t}}^{p r e d}-\sigma_{p v_{t}}^{d o w n}\left(1-\alpha_{p v}\right) \leq P_{p v, p_{t}}^{r t} \leq P_{p v_{t}}^{p r e d}+\sigma_{p v_{t}}^{u p} \alpha_{p v} \\
& P_{p v_{t}}^{r t}=P_{p v i n n_{t}}^{r t}+P_{p v, o u t_{t}}^{r t} \\
& 0 \leq S_{p v_{t}} \leq P_{p v, p_{t}}^{r t}
\end{aligned}
$$

In Eq. (13), $P_{p v, p_{t}}^{r t}$ is the forecasted PV power generation, $\sigma_{p v_{t}}^{d o w n} / \sigma_{p v_{t}}^{u p}$ is the upper/lower variance of the prediction. Besides, $\alpha_{p v}$-Optimistic Coefficient $(O C)$ - is defined as a parameter that its amount is between 0 and 1 . The amount of $\alpha_{p v}$ is set by the decision-maker of the MASHES. Eq. (14) represents that the total power output of the PV system equals its power output consumed in the home, $P_{p v, i n_{t}}^{r t}$, and the amount of power generation that is sold to the RTLEM, $P_{p v, \text { out }_{t}}^{r t}$. The spillage amount of the PV system is the amount of power that is spilled in period t. This amount is positive or equal to zero, and is limited to the actual power generation of the PV panels as presented in Eq. (15).

2) EV: The EV can be utilized based on the charge and discharge strategies in the DEM problem. 


$$
\begin{aligned}
& C_{t}=C_{t-1}+P_{c h_{t}}^{r t} \eta_{B 2 V}-P_{\text {dis }_{t}}^{r t} / \eta_{V 2 B}, t \geq 2 \\
& C_{t}=C_{i}, t=1 \\
& P_{e v}^{\text {min }} \leq C_{t} \leq P_{e v}^{\max } \\
& -w^{\text {min }} \leq C_{t}-C_{t-1} \leq w^{\max }, t \geq 2 \\
& -w^{\text {min }} \leq C_{t}-C_{i} \leq w^{\text {max }}, t=1 \\
& 0 \leq P_{\text {dist }}^{r t} \leq w^{\text {max }} u_{t} \\
& 0 \leq P_{c h_{t}}^{r t} \leq w^{\text {min }}\left(1-u_{t}\right) \\
& P_{\text {dist }}^{r t}=P_{\text {dis, in }}^{r t}+P_{\text {dis,out }}^{r t}
\end{aligned}
$$

Eq. (16) represents the state of charge balance equation of the $\mathrm{EV}$ in the real-time, where $C_{i}$ is the initial state of charge in the EV. Eq. (17) represents the state of charge balance equation in an EV. Eq. (18) represents the maximum and minimum limitations of the EV's state of charge. Maximum and minimum limitations of the discharge current are represented in Eq. (19). Moreover, Eq. (20) expresses the constraint of the $\mathrm{EV}$ in the charge state. The discharge power of the EV, $P_{d i s_{t}}^{r t}$, is expressed in Eq. (21).

\section{Electrical Loads}

ELs consist of loads that can be controllable and/or shiftable. Equations (22) and (23) define total electrical load and total load shedding, respectively.

$$
\begin{aligned}
& \sum_{j=1}^{N_{j}} L_{j_{t}}^{r t}=L_{s h_{t}}^{r t}+L_{s w h_{t}}^{r t}+L_{m r s_{t}}^{r t} \\
& \sum_{j=1}^{N_{j}} L_{j_{t}}^{\text {shed }}=L_{s h_{t}}^{\text {shed }}+L_{s w h_{t}}^{\text {shed }}+L_{m r s_{t}}^{\text {shed }}
\end{aligned}
$$

1) Space Heater: The space heater provides the indoor temperature at the desired temperature. Eq. (24) defines the relation between the indoor temperature and the electrical load of the space heater. In Eq. (24), $\theta_{0}$ is the initial indoor temperature which is assumed to be equal the desired temperature. Eq. (25) represents that indoor temperature is limited to $1^{\circ} \mathrm{C}$ more and less than the desired temperature. Also, the maximum and minimum bands of the space heater load is stated in Eq. (26). Besides, the load shedding limitation of the space heater is represented in Eq. (27).

$$
\begin{aligned}
& \theta_{\text {in }_{t}+1}=\theta_{i n_{t}} e^{-1 / R C}+L_{s h_{t}}^{r t} R\left(1-e^{-1 / R C}\right) \\
& +\theta_{\text {out }_{t}}^{\text {pred }}\left(1-e^{-1 / R C}\right), t \geq 2 \\
& \theta_{\text {in }_{t}}^{r t}=\theta_{0}=\theta_{\text {des }}, t=1 \\
& -1 \leq \theta_{\text {in }_{t}}^{r t}-\theta_{\text {des }} \leq 1 \\
& L_{s h_{t}}^{\text {min }} \leq L_{s h_{t}}^{r t} \leq L_{s h_{t}}^{\max } \\
& 0 \leq L_{s h_{t}}^{\text {shed }} \leq L_{s h_{t}}^{r t}
\end{aligned}
$$

2) Storage Water Heater: Storage water heater is in charge of storing the heat in the water tank. The maximum and minimum constraints of the storage water heater's power and energy consumption are stated in Eq. (28) and (29), respectively. The load shedding constraint related to the storage water heater is represented in Eq. (30).

$$
\begin{aligned}
& L_{s w h_{t}}^{\min } \leq L_{s w h_{t}}^{r t} \leq L_{s w h_{t}}^{\max } \\
& \sum_{t=1}^{N_{t}} L_{s w h_{t}}^{r t}=U_{s w h_{t}} \\
& 0 \leq L_{\text {swed }}^{\text {shed }} \leq L_{\text {swh }}^{r t}
\end{aligned}
$$

3) Pool Pump: The pool pump should not run more than $T_{O N}$ hours in a day. Eq. (31) represents the maximum and minimum bands of the pool pump load in each hour.

$$
\begin{aligned}
& L_{p p_{t}}^{\min } z_{t} \leq L_{p p_{t}}^{r t} \leq L_{p p_{t}}^{\max } z_{t} \\
& \sum_{t=1}^{N_{t}} z_{t} \leq T_{O N}
\end{aligned}
$$

4) Must-Run Services: Must-run services include the loads that should be provided quickly - e.g. lighting, entertainment, etc. The load shedding constraint is stated by Eq. (34).

$$
\begin{aligned}
& L_{m r s_{t}}^{r t}=L_{m r s_{t}}^{\text {pred }} \\
& 0 \leq L_{m r s_{t}}^{\text {shed }} \leq L_{m r s_{t}}^{r t}
\end{aligned}
$$

\section{Proposed Hardware Implementation}

As it has been mentioned, this paper includes a domestic energy management system based on MAS and distributed control fashion. The electrical loads considered for this system have been categorized in three main types:

- Controllable loads: This category includes the loads that their consumption can be reduced or curtailed;

- Shiftable loads: This category consists of the electrical loads that their consumption can be shifted from a period of time to other certain periods, without any reduction or curtailment;

- Must-run loads: This group contains such electrical loads that their consumption cannot be controlled, shifted, or curtailed.

In this system, a space heater is considered as a controllable load. The space heater is related to a home appliance, which provides the indoor temperature at the desired temperature. The maximum capacity specified for this load is $5.525 \mathrm{~kW}$. Storage water heater and pool pump are the other electrical loads considered as shiftable loads. The storage water heater is in charge of storing the heat in the water tank, and the pool pump is a part of swimming pool installations. The energy capacity of the storage water heater is $10.46 \mathrm{kWh}$ $(180 \mathrm{~L})$, which has $2 \mathrm{~kW}$ heating element. The rated power of the pool pump is $1.1 \mathrm{~kW}$, and it is considered that it can operate for a maximum of 6 hours during the day. Additionally, several types of loads, such as lighting, or entertainment, are considered as must-run loads.

The maximum energy produced by the PV system is 2.5 $\mathrm{kWh}$. Furthermore, an EV is propounded for the system playing the role of an ESS. This ESS unit can store energy between 1.77 and $5.9 \mathrm{kWh}$, and its maximum charging/discharging 


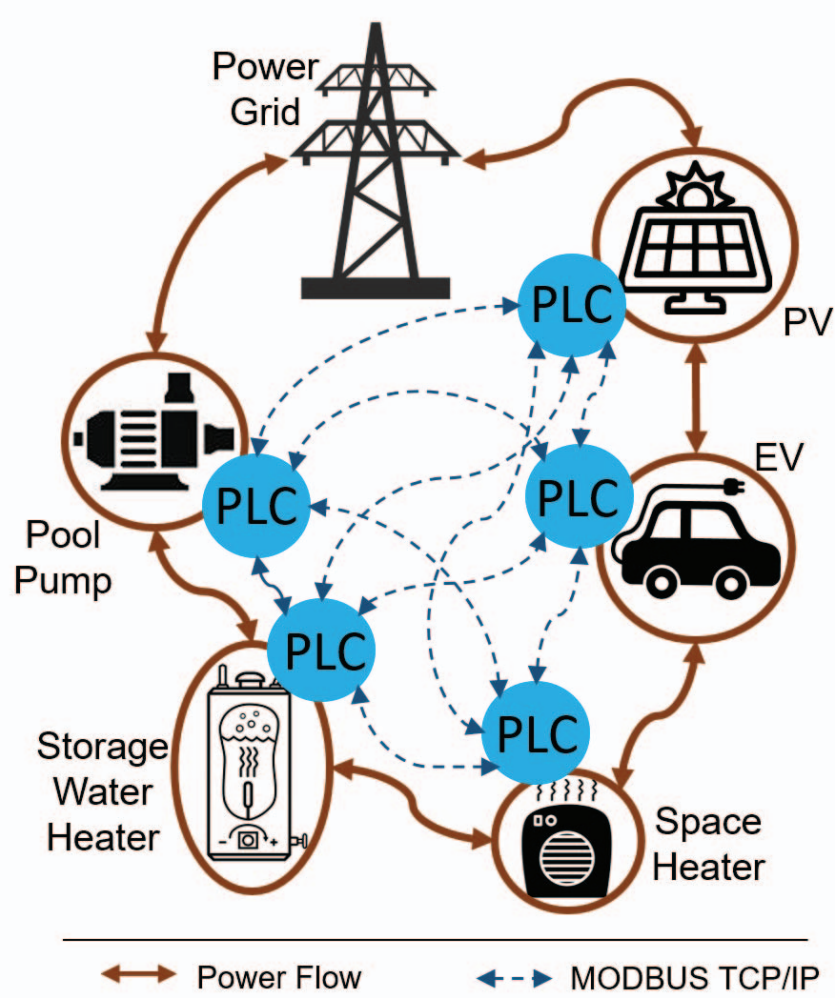

Fig. 3. Proposed MAS architecture for the system control.

rates are $3 \mathrm{~kW}$. Besides, charging and discharging efficiencies are $90 \%$. Fig. 3 represents the overall system architecture. In this system, the PV and ESS can supply the local demand, and while there is more generation than the local demand, the system is able to inject the excess of the produced power to the utility grid.

As Fig. 3 shown, there are five main agents namely, PV, EV, Water Heater, Space Heater, and Pool Pump agent. As also illustrated in Fig. 4, each agent is equipped with a Programmable Logic Controller (PLC) in order to perform decision-making locally and communicate with other agents to fulfill the overall systems goal.

Moreover, Fig. 4 presents the deployment diagram which addresses the static realization of the system. In this figure, each agent is represented by its corresponding representation in UML deployment diagram called node. A node consists of several components which are the instances of the components shown in Fig. 3. The nodes are communicated via Ethernet interface, with MODBUS TCP/IP protocol. The agents constantly exchange messages in order to share their latest status in the network. This will reduce the response time to any changes in the agents and hence improve the adaptability. On the other hand, flexibility and reconfigurability are two main important characteristics that an agent-based system offers. For instance, any faulty machine or agent can be easily repaired and replaced without any disruption in the overall systems task.

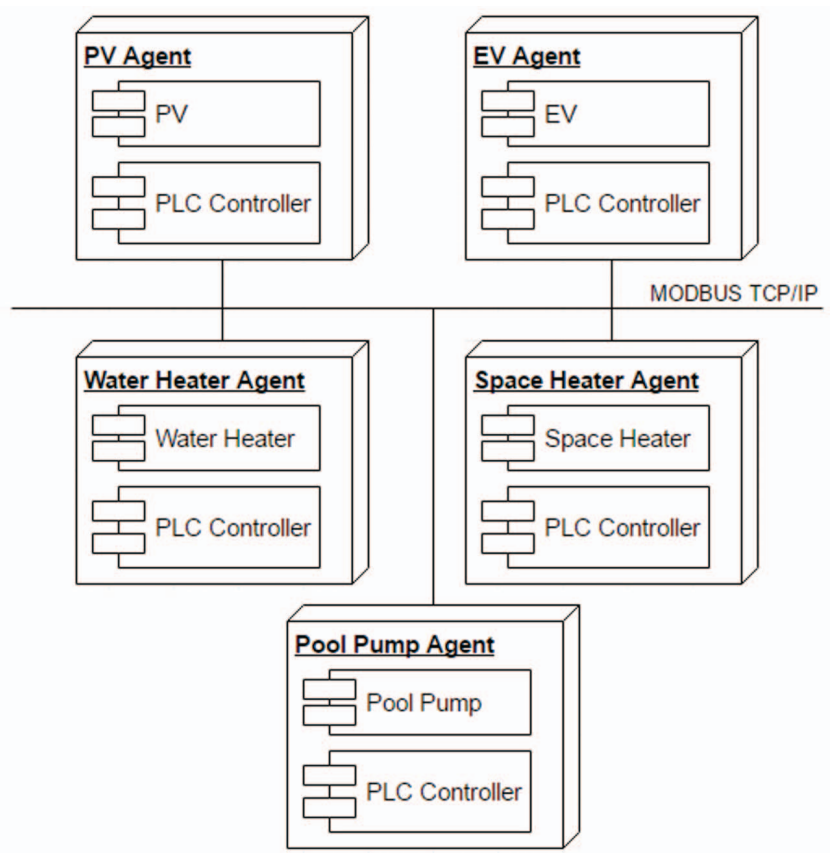

Fig. 4. Agent-based deployment diagram.

\section{Simulation Results}

A physical system from [17] is used to evaluate the performance of the proposed DEMS. However, some modifications of the system parameters are made. For instance, the predicted data of PV power generation and the must-run services are used from [18]-[20]. The performance of the proposed DEM model is assessed in three cases. The program implemented is solved in GAMS 23.7 [21]. In this section, the performance of proposed DEMS is studies in two cases: Case 1: Effect of PV system, and Case 2: Effect of EV.

\section{A. Impact of PV system}

The impact of the PV system on the expected profit is evaluated in three scenarios in this section. In Scenario 1, PV system is not considered in the MASHES. In Scenario 2, the proposed DEMS is assesssed when $\alpha$ equals 0 and 1 . In Scenario 3, uncertainty of PV generation is not considered. Table I states the amount of expected profit and energy produced by the PV system in the RT stage. As seen in Table I, the expected profit is highest in Scenario 2 when $\alpha$ equals 1 , because it is the optimistic scenario of PV power generation. Besides, the results of the system in Scenario 2 when $\alpha$ equals 0 is equal to the results of the Scenario 3 that uncertainty of PV power generation is not considered because the power generation of the PV system tends to converge to the central forecasting when $\alpha$ equals zero. Moreover, Table II describes the amounts of the day-ahead, real-time, and total expected profits of the system in Scenario 1. As seen in Table II the total and day-ahead expected profits are negative because PV generation is equal to zero and DEMS must provide its electrical demand from the electricity market. However, $E P^{r t}$ 


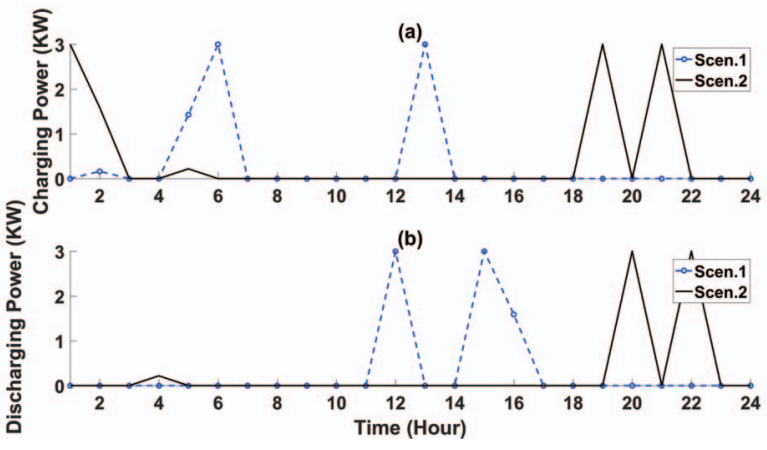

Fig. 5. Impact of (a) Charging power of EV., (b) Discharging power of EV.

is positive because of flexibility influence of the EV in the RTLEM.

TABLE I

IMPACT OF PV SYSTEM ON THE EXPECTED PROFIT AND TOTAL ENERGY PRODUCED BY THE PV SYSTEM.

\begin{tabular}{|c|c|c|c|c|}
\cline { 2 - 5 } \multicolumn{1}{c|}{} & \multicolumn{4}{c|}{ PV System } \\
\cline { 2 - 5 } \multicolumn{1}{c|}{} & Scen. 1 & Scen. 2( $\alpha=0)$ & Scen. 2( $\alpha=1)$ & Scen. 3 \\
\hline$E P$ & -6.142 & 9.962 & 10.132 & 9.962 \\
\hline$E_{p v}^{r t}$ & 0 & 7.32 & 8.41 & 7.32 \\
\hline
\end{tabular}

TABLE II

DAY-AHEAD, REAL-TIME, AND TOTAL EXPECTED PROFITS WITHOUT CONSIDERING PV SYSTEM.

\begin{tabular}{|c|c|c|c|}
\cline { 2 - 4 } \multicolumn{1}{c|}{} & \multicolumn{3}{c|}{ Without PV System } \\
\cline { 2 - 4 } \multicolumn{1}{c|}{} & $E P$ & $E P^{d a}$ & $E P^{r t}$ \\
\hline Scenario 1 & -6.142 & -11.268 & 5.126 \\
\hline
\end{tabular}

\section{B. Impact of $E V$}

The impact of the EV is assessed in two scenarios in this section. In Scenario 1, EV is available in all hours in the MASHES, and plays as the battery in the system. In Scenario 2 , EV is out of home in period 6-17. Also, it is assumed that the EV should be full of charge at 6 , and it has the minimum capacity at 17 . Moreover, $\alpha$ is set to be 0 in this section. As seen in Table III, the expected profit of the system in Scenario 1 is more than Scenario 2 because the EV is completely available at home in Scenario 1. Besides, there is no any constraint to force the state of charge of the EV in some specific times in Scenario 1. On the other hand, the bought electrical energy from the LEM is less in Scenario 1. However, Scenario 1 increases the sold electrical energy to the LEM.

\section{Vi. Conclusions}

In this paper, the multi agent-based smart home electricity system has been presented. The performance of the proposed domestic energy management model that be able to transact electrical energy with the local electricity market has been assessed based on the impacts of PV system and EV. Also,
TABLE III

IMPACT OF EV ON THE TOTAL EXPECTED PROFIT, THE BOUGHT/SOLD ENERGY FROM/TO THE LOCAL ELECTRICITY MARKET.

\begin{tabular}{|l|c|c|c|}
\cline { 2 - 4 } \multicolumn{1}{c|}{} & \multicolumn{3}{c|}{ EV } \\
\cline { 2 - 4 } \multicolumn{1}{c|}{} & $E P$ & $E_{\text {bought }}^{\text {rt }}$ & $E_{\text {sold }}^{\text {rt }}$ \\
\hline Scenario 1 & 11.598 & 34.791 & 14.909 \\
\hline Scenario 2 & 9.962 & 36.510 & 13.538 \\
\hline
\end{tabular}

the HyFIS has been utilized in the predictor system. An interval method has been used to model the uncertainty of the PV power generation according to the central and error (variance) of forecasting. This way, optimistic coefficient has been defined that its amount is set by the decision-maker in the domestic energy management system, and its amount is between 0 and 1 . The proposed hardware implementation demonstrated that multi agent model reduces the response time to any changes in the agents and hence improve the adaptability of the system. Additionally, flexibility and reconfigurability are two main important characteristics that an agent-based microgrid offers. From the simulation, considering the $\mathrm{EV}$ in the real-time stage of the proposed domestic energy management problem increases the energy flexibility in the home. Besides, it increases the expected profit of the domestic system and improves its autonomous utilization.

\section{ACKNOWLEDGMENT}

This work has been supported by the European Commission H2020 MSCA-RISE-2014: Marie Sklodowska-Curie project DREAM-GO Enabling Demand Response for short and realtime Efficient And Market Based Smart Grid Operation - An intelligent and real-time simulation approach ref. 641794.

\section{REFERENCES}

[1] P. Faria, and Z. Vale, "Demand response in electrical energy supply: An optimal real time pricing approach", Energy," vol. 36, no. 8, pp. 53745384, 2011.

[2] J T. Wang, D. ONeill, and H. Kamath, "Dynamic Control and Optimization of Distributed Energy Resources in a Microgrid," IEEE Transactions on Smart Grid, vol. 6, no. 6, pp. 2884-2894, 2015.

[3] O. Abrishambaf, L. Gomes, P. Faria, J. L. Afonso and Z. Vale, "Real-time simulation of renewable energy transactions in microgrid context using real hardware resources," 2016 IEEE/PES Transmission and Distribution Conference and Exposition (T\&D), Dallas, TX, 2016, pp. 1-5.

[4] Z. Vale, H. Morais, P. Faria and C. Ramos, 'Distribution system operation supported by contextual energy resource management based on intelligent SCADA," Renewable Energy, vol. 52, pp. 143-153, 2013.

[5] O. Abrishambaf, M. A. F. Ghazvini, L. Gomes, P. Faria, Z. Vale and J. M. Corchado, "Application of a Home Energy Management System for Incentive-Based Demand Response Program Implementation," 2016 27th International Workshop on Database and Expert Systems Applications (DEXA), Porto, 2016, pp. 153-157.

[6] Qiang Wan, W. Zhang, Y. Xu and I. Khan, "Distributed control for energy management in a microgrid," 2016 IEEE/PES Transmission and Distribution Conference and Exposition (T\&D), 2016.

[7] R. Abrishambaf, M. Hashemipour and M. Bal, "Structural modeling of industrial wireless sensor and actuator networks for reconfigurable mechatronic systems," The International Journal of Advanced Manufacturing Technology, vol. 64, no. 5-8, pp. 793-811, 2012.

[8] R. de Azevedo, M. Cintuglu, T. Ma and O. Mohammed, "Multi-Agent Based Optimal Microgrid Control Using Fully Distributed Diffusion Strategy," IEEE Transactions on Smart Grid, pp. 1-1, 2016. 
[9] [9] X. Chen, Y. Hou and S. Hui, "Distributed Control of Multiple Electric Springs for Voltage Control in Microgrid," IEEE Transactions on Smart Grid, pp. 1-1, 2016.

[10] P. Leitao, "Agent-based distributed manufacturing control: A state-ofthe-art survey," Engineering Applications of Artificial Intelligence, vol. 22, no. 7, pp. 979-991, 2009.

[11] G. Santos, T. Pinto, I. Praa and Z. Vale, "MASCEM: Optimizing the performance of a multi-agent system", Energy, vol. 111, pp. 513-524, 2016.

[12] J. Kim, N. Kasabov, "HyFIS: adaptive neuro-fuzzy inference systems and their application to nonlinear dynamical systems," Neural Networks, Volume 12, Issue 9, November 1999, Pages 1301-1319, ISSN 0893-6080.

[13] F. Gomide and W. Pedrycz, "Notions and Concepts of Fuzzy Sets," Fuzzy Systems Engineering: Toward Human-Centric Computing, 2007.

[14] L. X. Wang and J. M. Mendel, "Generating fuzzy rules by learning from examples," Intelligent Control, 1991., Proceedings of the 1991 IEEE International Symposium on, Arlington, VA, 1991, pp. 263-268.

[15] A. Jozi, T. Pinto, I. Praa, F. Silva, B. Teixeira and Z. Vale, "Energy consumption forecasting based on Hybrid Neural Fuzzy Inference System," 2016 IEEE Symposium Series on Computational Intelligence (SSCI), Athens, 2016.

[16] K. Rudd, G. Di Muro and S. Ferrari, "A Constrained Backpropagation Approach for the Adaptive Solution of Partial Differential Equations," IEEE Trans. on Neural Networks and Learning Systems, vol. 25, no. 3, pp. 571,584, Mar. 2014.

[17] M. Pedrasa, T. Spooner, and I. MacGill, "Improved energy services provision through the intelligent control of distributed energy resources," in Proc. 2009, IEEE Bucharest power Tech conf.

[18] A. Shokri Gazafroudi, F. Prieto-Castrillo, and J. M. Corchado, "Residential Energy Management Using a Novel Interval Optimization Method," Accepted: 4th International Conference on Control, Decision and Inf. Tech., April 2017.

[19] A. Shokri Gazafroudi, T. Pinto, F. Prieto-Castrillo, J. Prieto, J. M. Corchado, A. Jozi, Z. Vale, G. K. Venayagamoorthy, "Organization-based Multi-Agent Structure of the Smart Home Electricity System," in Proc., 4th IEEE Cong. on Evolut. Comp., June 2017.

[20] A. Shokri Gazafroudi, F. Prieto-Castrillo, T. Pinto, A. Jozi, Z. Vale, "Economic Evaluation of Predictive Dispatch Model in MAS-based Smart Home," in Proc., 4th IEEE Cong. on Evolut. Comp., June 2017.

[21] GAMS Release 2.50. A users guide. GAMS Development Corporation,1999. Available: http://www.gams.com. 